\title{
Introducción El concepto actual de Patrimonio Cultural
}

María Morente del Monte

Directora del Museo de Málaga y Profesora de la Universidad de Málaga

No estamos yendo de espaldas hacia el futuro, como el Angelus novus descrito por Walter Benjamin, reducidos a avanzar mientras lanzamos miradas desesperadas hacia atrás? Pero, ¿no es el patrimonio algo completamente diferente?. ¿No se trata más de una promesa que de una posesión, de una pregunta más que de una certeza, de un proyecto de futuro más que de un tesoro antiguo? De una bolsa de viaje, si se quiere, pero una bolsa cuya llave siempre parece estar extraviada. Un tesoro, tal vez, cuyo "ábrete sésamo" todavía tenemos que descubrir... (François Ost, 2002)

Uno sólo se pregunta qué son las cosas cuando estas presentan una cierta incertidumbre o cuando piensa que su verdadera esencia queda oculta tras la persuasión de su apariencia. Precisamente por esto me atrae la reflexión sobre el patrimonio, porque creo que se trata de un fenómeno que requiere repensarse; que no ha dejado de mutarse y alterarse; que se presta a interpretaciones; que es opinable.

Pero los debates conceptuales suelen quedar ensombrecidos ante la inminencia de la acción, sobre todo en casos como el del patrimonio, sujetos a financiación y servicios públicos que precisan predicar eficacia y celeridad de sus actuaciones. Configuramos patrimonio entremezclando nuevas creaciones con permanencias; hacemos y rehacemos continuamente objetos, ideas, prácticas o paisajes y, en esta actividad constante, nos preocupa ante todo el "cómo hacer", sobre todo ahora, en estos tiempos en que la funcionalidad y la utilidad se han erigido como principio de toda práctica. Como en otras disciplinas, en el patrimonio hemos prestado también una atención preferente a los métodos y sus instrumentos. Ya no protegemos, conservamos, restauramos, investigamos o difundimos nuestros patrimonios de la misma forma que hace un siglo, pero tampoco con el mismo sentido ni objetivo. Los tradicionales historiadores del arte, arqueólogos, arquitectos o restauradores se han visto en la necesidad de reciclarse. Incluso hemos llegado a formalizar nuevos oficios o profesiones: conservadores de patrimonio, arqueólogos de gestión, técnicos de patrimonio (esos asesores que las entidades locales empiezan a contratar como personas versátiles capaces de realizar desde un informe histórico a un planeamiento urbanístico, desde la gestión de una exposición temporal a los contenidos de un museo o la organización de una biblioteca o un archivo) o nuevos expertos en comunicación, interpretación y nuevas tecnologías aplicadas los productos culturales y patrimoniales. Se hace evidente que el actual Patrimonio requiere una formación especial precisamente por lo que es, por lo que representa, por su valor, significado o utilidad.

Me he observado a mí misma en muchas ocasiones reflexionando en alto un pensamiento que puede resultar realmente extraño fuera de su contexto: el patrimonio se ve o no se ve; es como la fe: se cree o no se cree. Salvando las distancias de esta comparación, creo que es cierto. Siempre dedico en mis clases un esfuerzo considerable a que mis alumnos de Historia del Arte comprendan la diferencia entre el objeto histórico artístico y el objeto patrimonial. Muchos historiadores, procedan del mundo del arte, de la arqueología o de otra especialidad, se consideran dedicados al Patrimonio porque estudian bienes históricos. Los que nos dedicamos a esto sabemos desde hace tiempo que el patrimonio constituye mucho más; algo diferente a la suma de objetos de distinta naturaleza y que, por tanto, su metodología responde también más que la suma de disciplinas o ciencias plurales (historia del arte + arqueología + arquitectura + antropología + conservación $+\ldots)$. Ciertamente, identificamos y protegemos como patrimonio objetos y bienes de distintas tipologías o naturalezas, por lo que hay que contar con especialistas de cada una de ellas. Pero la dimensión del bien patrimonial no se agota en estos valores, sino que además de ellos, a modo de característica compartida, de requisito de obligado cumplimiento, cada patrimonio ha de poseer, al menos de un tiempo hacia acá, un sentido social, una capacidad de ser expresión de identidades culturales, una cierta funcionalidad práctica y significativa.

Este planteamiento fundamenta uno de los cambios cualitativos más importantes que ha experimentado el patrimonio desde el siglo XIX hasta nuestros días. Porque los métodos y la profesión han cambiado, al transformarse también el propio patrimonio. Su concepto ha evolucionado esencialmente y justifica que tratemos a los bienes patrimoniales con metodologías diferentes.

Pero siendo prácticos, podriamos preguntarnos ¿para qué debatir y teorizar tanto sobre qué es y qué no, patrimonio; qué ha sido en otros momentos o qué representa ahora? ¿qué sentido tiene teorizar cuando nos falta tiempo para actuar, para proteger, para diseñar proyectos, para generar actuaciones de difusión? En definitiva, ¿qué interés tiene dedicar un número de Debate e Investigación de PH al concepto actual de Patrimonio? Podria ofreceros muchas respuestas ante estas preguntas. Ante todo me preside una convicción: la importancia de la comprensión, la trascendencia que tiene el concepto que formulemos. En la gestión administrativa diaria, a la que me he dedicado los veinte últimos años, he comprobado que muchas de las deficiencias no responden tanto a carencias de metodología o de recursos, como de concepto. Muchos de los conflictos patrimoniales a los que asistimos como protagonistas o espectadores diariamente dejan traslucir posturas que responden a un concepto trasnochado de patrimonio o a una falta de comprensión del alcance o significado actual que poseen los bienes culturales en nuestro mundo contemporáneo.

El concepto de patrimonio que profesemos determinará el universo de bienes susceptibles de considerarse como tal patrimonio y, sin duda, delimitará su función y aplicaciones y sus posibles metodologías. Estas determinaciones son las propias de cualquier ciencia y mantienen una duda que exponiamos hace ya años: ¿llegará el Patrimonio a contar algún día con una disciplina o ciencia propia? (Morente, 1996). La falta de una disciplina específica ha ocasionado que el debate y la definición de patrimonio avancen de forma lenta, poco consensuada y sin el apoyo de un corpus doctrinal específico, a diferencia de lo que ha ocurrido en otros campos cercanos de la practica profesional, por ejemplo en la Museología. En este caso se han formulado y teorizado la evolución de los bienes culturales amparados por la institución del Museo y se han descrito unos procesos y elaborado unos procedimientos aplicables en gran medida al patrimonio que queda fuera de dichas instituciones ${ }^{1}$. 
Desde luego, los cambios que ha conocido el patrimonio desde su institucionalización en el siglo XIX permite ya que hablemos de una historiografía propia, en la que se pueden destacar unos momentos de inflexión claves. Entre otros, tras las dos guerras mundiales se hace evidente la crisis de los estados liberales y el nuevo papel del Estado Social, legitimado por la prestación de unos servicios sociales, entre los que encontrará un protagonismo preferente la cultura, como ratifican las nuevas constituciones democráticas del siglo XX. La crisis trascendental, por otra parte, se hará sentir en una reformulación del papel de la historia. La superación de la historia como clave exclusiva de legitimación de nuestro patrimonio y la aceptación de la cultura como nuevo argumento, a partir de los años sesenta, nos vino a liberar de los preceptos y prácticas de la tradición y nos permitió formular ciertos guiños a lo cotidiano o a lo contemporáneo, como fuentes de suministro de los nuevos bienes culturales.

A partir de entonces, los valores o criterios de demarcación del patrimonio dejan de ser inmutables y quedan sujetos a un proceso continuo de revisión, caracterizado por la posibilidad de infinitas elecciones. Circunstancia que ha sustentado igualmente el proceso de revisión de las Ciencias Sociales y que al fin y al cabo se reconoce como una de las características definitorias de lo que ha venido a llamarse el escenario de la postmodernidad (Giddens, 1997). Tanto en la vida diaria como en la conciencia filosófica, cada planteamiento/aserción adquiere ahora el carácter de una hipótesis siempre susceptible de consideración y abandono en cualquier momento. El revisionismo impregna al concepto de patrimonio y nos hace conscientes, en cada decisión, de que los criterios ya no son los que fueron ni los que serán en otro tiempo; que el universo de los bienes, igualmente, puede ser provisional y cambiante.

También es cierto que, ante tanta incertidumbre, surgen propuestas que intentan evitar la posibilidad de equivocación. Así se empieza a adoptar en el mundo del patrimonio la alternativa de los economistas de mantener abiertas las opciones, considerando que la mejor forma de conservación del patrimonio puede llegar a ser mantener la integridad de nuestro planeta, evitando actos irreversibles, pues nadie nos asegura el gusto o necesidades que van a tener esas generaciones del futuro, destinatarias últimas de nuestro legado patrimonial (Canclini, 1995) (Castells, 1997).

El valor cultural como esencia de la cualidad patrimonial ha generado también un cierto efecto collage: El patrimonio se haya, a partir de entonces, conformado por una diversidad de bienes de naturaleza y tipologías heterogéneos, cada vez más dispar. A su vez la apuesta por la cultura le hace entrar de lleno en los discursos vinculados con la identidad y la globalización. La tendencia universalista del patrimonio actual interacciona con los valores interpretativos y el contexto de los compromisos locales. La fragmentación de comunidades culturales diferentes se desvanece ante los efectos de la globalización, donde la presencia del nosotros elude el interés y la diferenciación de los otros. Pese a esta situación, las políticas del patrimonio insisten en reforzar la selección de los bienes aun representativos de las diferencias; desempeñando además un papel destacado ante el nuevo escenario que está configurando la mezcla de identidades y culturas por el efecto de las migraciones (Appadurai, 1986).

No obstante, y pese a estos roles, la conversión del bien patrimonial en producto cultural lleva implícita su mercantilización como artículo consumible, asociado ante todo a las estrategias del turismo o a las demandas de la sociedad del ocio, donde se desatienden los criterios de la autenticidad en pro de las reglas economicistas del mercado. Frente a esta tendencia, existen aún actuaciones y políticas honestas, aunque no exentas del riesgo que supone la construcción o el reforzamiento de las identidades culturales y las ideologias.

Incluso la actual posibilidad de que todo pueda llegar a ser patrimonio ha sido interpretada por algunos pensadores contemporáneos como una reacción de miedo ante un mundo dominado por el mercado, ya que de alguna forma, y retomando a Fromm, el patrimonio viene a sustituir el tener por el ser y permite combatir la tendencia de la sociedad del despilfarro a reducir la vida a un presente instantáneo. El patrimonio tal vez nos permita recobrar una perspectiva temporal y volvernos conscientes del pasado del cual venimos y del futuro hacia el que vamos (Remond- Gouilloud, 2002).

Francois Ost, cuyas palabras encabezan este texto, retoma en el mismo artículo un precioso pasaje de Primo Leví, rememorando el valor evocador y esperanzador que pueden alcanzar unos fragmentos de la Divina Comedia, mal recordados por dos presos en el campo de concentración de Auschwitz en 1944. Estos versos se constituyen en ese momento en patrimonio, en una herencia sin testamento; portadores de un contenido que nunca se extingue, que es significativo porque se transmite y que al transferirse adquiere un valor de presente: se reformula y se reescribe continuamente. Expresa asi Ost una de las connotaciones más decisivas que posee el patrimonio actual: un viraje en su dimensión temporal. Más que al pasado, el patrimonio es ya consciente de su compromiso y afán por el futuro: nuestra aportación ecológica a que los tiempos venideros no empeoren. Ante una realidad que se siente afectada en cualquier momento por sucesos contingentes, en la que nada permanece eterno e inmutable, el patrimonio genera la estabilidad no de la permanencia y la tradición, sino sobre todo de la posible construcción de un futuro.

Pese a los esfuerzos y a la convicción de que el patrimonio se legitima por el reconocimiento social, los productos patrimoniales siguen gozando de procesos selectivos, difícilmente democratizables, tanto en lo que se refiere a la identificación jurídica de dicho patrimonio, como a las intervenciones en los mismos. Si bien es cierto que fuera del estricto ámbito de la administración pública o del sector profesional -más ortodoxos- el patrimonio tiene límites menos definidos y la aceptación y reconocimiento social de objetos, lugares o expresiones de interés cultural no siempre coincide de forma estricta con el patrimonio jurídico, es decir especialmente protegido por las normas 


\begin{tabular}{l}
\hline Introducción \\
El concepto actual de \\
Patrimonio Cultural \\
María Morente del Monte
\end{tabular}

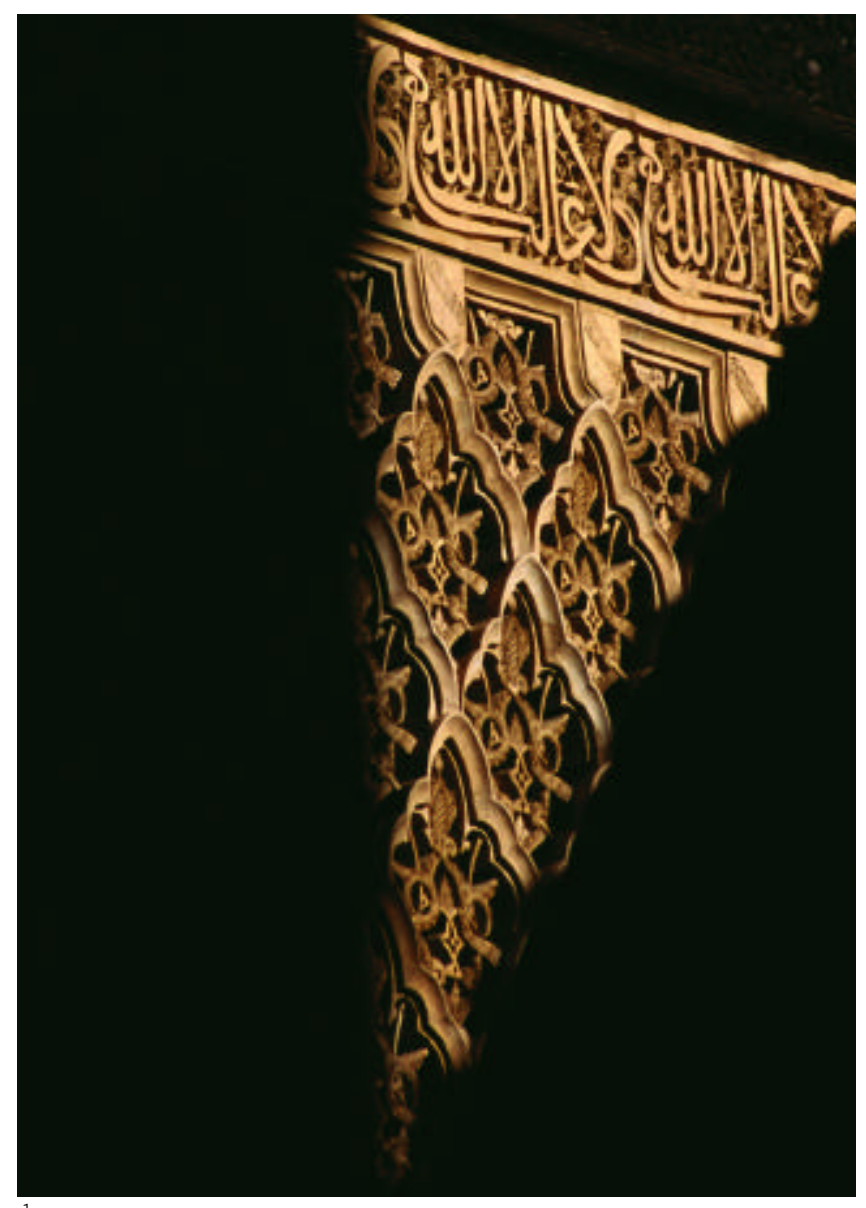

vigentes. Las legislaciones contemporáneas se han curado en salud en esta cuestión y definen como integrante del patrimonio cualquier objeto, manifestación o lugar que tenga un interés histórico, artístico, arqueológico, social, científico, técnico o cultural, en sentido amplio.

Además de los problemas de demarcación, el interés social como esencia del patrimonio ha reformulado la interpretación del mismo e incluso los procesos de intervención. Tenemos sobrados ejemplos. Las restauraciones atienden ya al valor de la imagen y al significado social de los bienes patrimoniales casi con la misma legitimidad que a otros criterios emanados de las disciplinas científicas y profesiones tradicionales. El nuevo código deontológico del Patrimonio parece sentirse obligado a considerar las expectativas sociales y su vinculación simbólica con el bien patrimonial y a justificar las intervenciones y hacerlas comprensibles y aceptables, más allá del cerrado círculo de los especialistas. El patrimonio se conforma ya también una ciencia social y de acción. La declaración jurídica no es ya el único acto constitutivo de la naturaleza patrimonial, sino que se hace imprescindible la aceptación social, el reconocimiento.

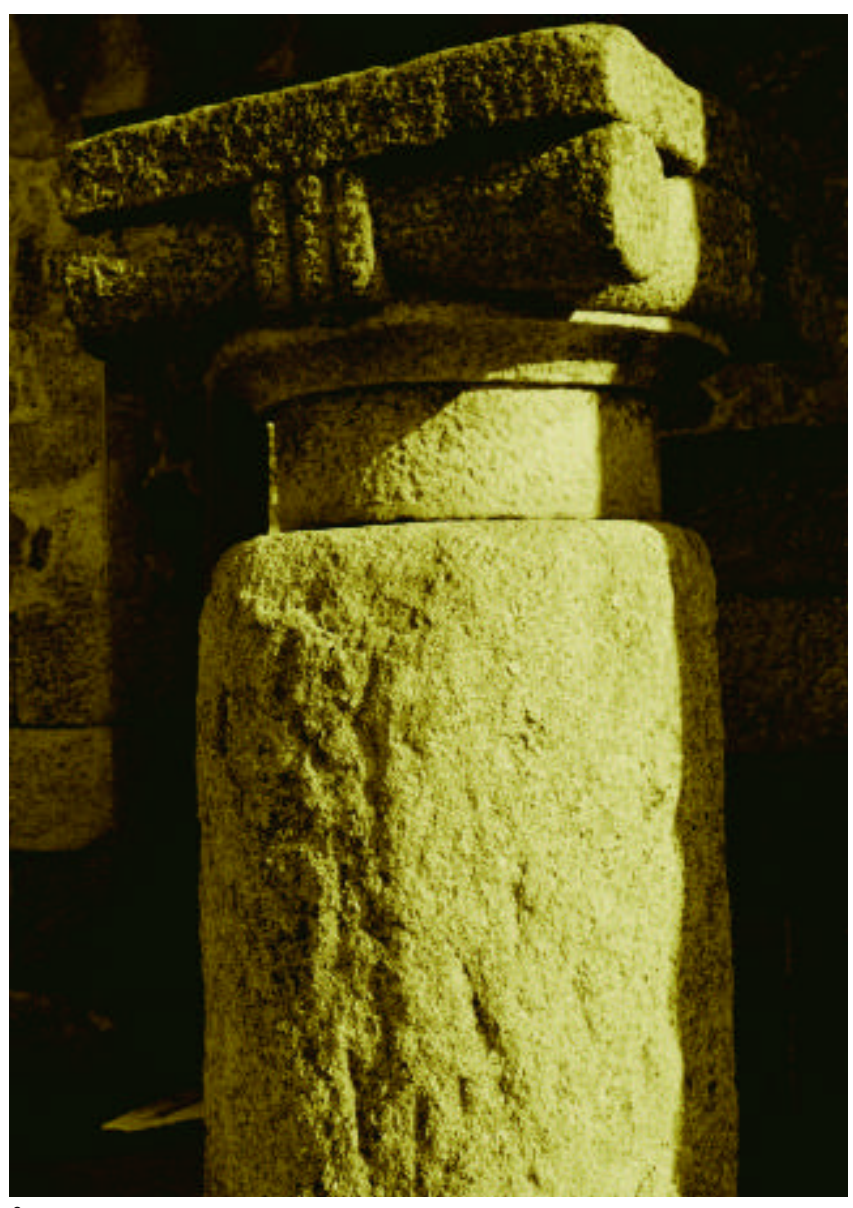

El patrimonio como bien común y social ha conocido también una refuncionalización. El nuevo producto patrimonial requiere el arrope de los instrumentos mediáticos de la didáctica, la interpretación y la comunicación, porque el bien patrimonial puede permanecer pero su significado siempre será cambiante. El patrimonio es ya algo que nos es dado, pero que también construimos y aparece cargado de potencialidades. Por tanto ha dejado de entenderse como algo finito, cerrado o concluso. La consideración reciente del genoma humano como patrimonio de la humanidad supone un ejemplo.

El afán por la interpretación y la comunicación denota el cambio del valor del objeto al valor de su mensaje, a una nueva dimensión icónica o mediática. Se demanda ahora, desde la propia sociedad, un desentrañamiento del mensaje de los bienes culturales, que ha de ser comprendido y no quedar reducido al grupo selecto de los especialistas. Pero la aplicación de nuevas tecnologías pueden no sólo llegar a presentar el patrimonio sino incluso a suplantarlo, generando nuevas relaciones entre el sujeto y el patrimonio. Un riesgo que ha de ser valorado. 
mágenes: Beatriz Carmona (1 y 3. Alhambra de Granada; 2. Teatro Romano de Mérida).

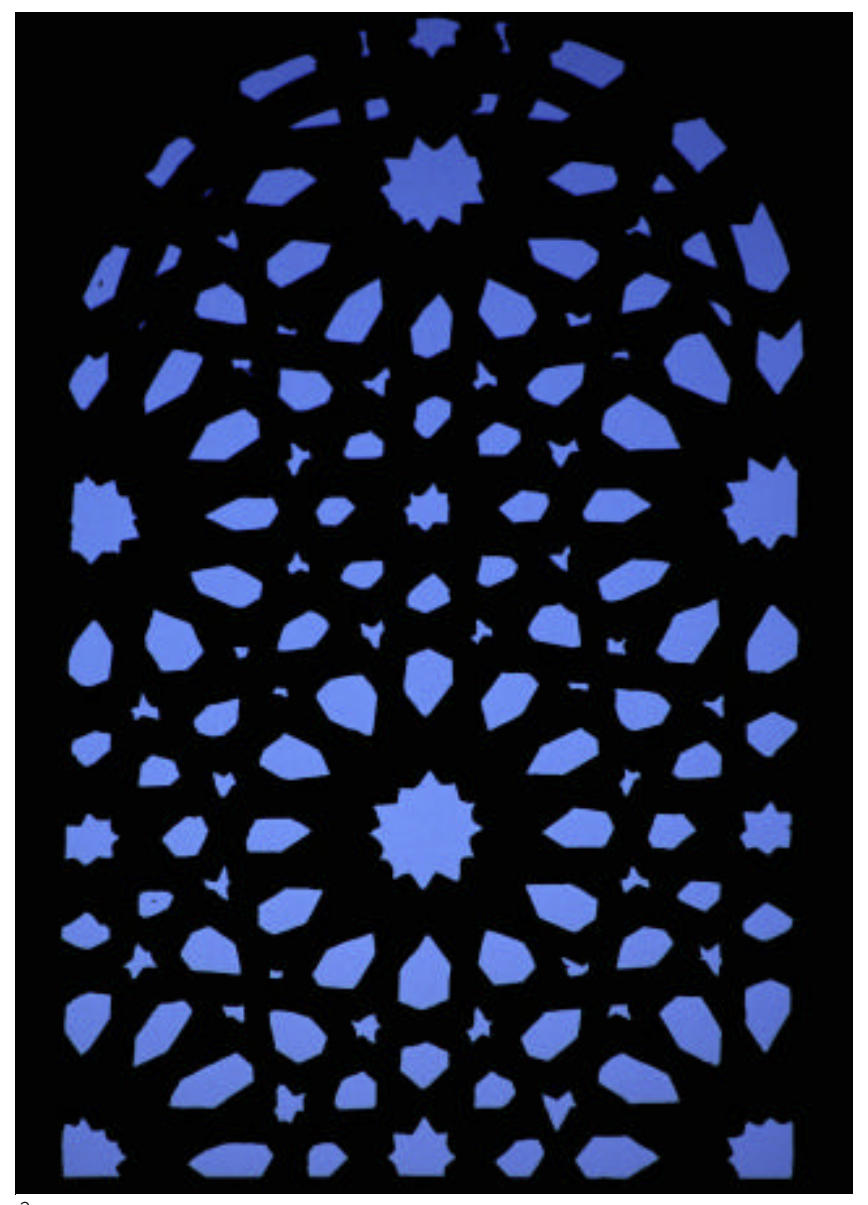

El patrimonio, inserto en el consumo de productos culturales, requiere igualmente ciertas dosis de seducción y espectáculo, imprescindibles a veces para asegurar su supervivencia y su accesibilidad social, en competencia a otros productos de consumo cultural. Frente a esto subsisten experiencias más tradicionales que prefieren seguir potenciando la comunicación estética objeto-espectador. Al igual que la museológica tradicional, los propios centros de Arte Contemporáneo parecen inclinados a esta tendencia, pese a la complejidad interpretativa de sus objetos. No así otros patrimonios que parecen depender de las nuevas tecnologías como única posibilidad de ser aceptados por el gran público. Un problema similar y complejo, pese a las solvencias de las teorías de la restauración, plantea la pervivencia del patrimonio y su adaptación a nuevos usos y funciones contemporáneas, donde la autenticidad de sus valores históricos y tipológicos parecen abocado a una confrontación y pugna con las nuevas necesidades.

Una última reflexión. El objeto patrimonial ha dejado de ser la meta y el objetivo de las actuaciones públicas, para convertirse en su medio. La propia UNESCO en sus programas, al igual que otros organismos internacionales, ha dejado de prestar una atención concreta al patrimonio (con esta denominación), para focalizar su atención preferente en las nuevas políticas estructurantes. El interés del objeto y el bien se encuentra subordinado a la necesidad de elaborar líneas estratégicas y planificaciones capaces de alcanzar fines más altos: la mejora de la calidad de vida, la preservación del medio ambiente y del planeta, la integración, la igualdad o la paz. El objetivo dejó hace tiempo de enfocar el objeto y el bien a favor de las personas, en su dimensión colectiva: la humanidad, eso sí con sus particularismos y diversidades culturales. Los métodos han pasado necesariamente también por una reformulación desde la tutela tradicional a la gestión y a la planificación estratégica ${ }^{2}$.

El concepto de Patrimonio fundamenta teóricamente y marca el verdadero alcance de nuestro pensamiento y nuestros actos. El Instituto Andaluz de Patrimonio Histórico siempre ha dedicado gran parte de sus recursos a provocar el debate y actualizar la reflexión. Le agradezco ahora la confianza que ha depositado en mi para que este número, dedicado al concepto actual de Patrimonio, vea la luz. En él quedan expuestos pensamientos, experiencias, proyectos y deseos dispares, emitidos desde sectores, situaciones y ámbitos muy diversos. Estas opiniones y otras muchas pueden ser útiles a nuestras reflexiones, nuestras incertidumbres y a esa continua búsqueda en este complejo y apasionante camino que es el patrimonio.

\section{Notas}

${ }^{1}$ Sobre todo a partir de los años ochenta del pasado siglo XX con la formulación de la Nueva Museologia y los trabajos entre otros de Riviere. Desvallées o Doucet.

${ }^{2}$ Entre otros documentos de UNESCO: Conferencia Intergubernamental sobre las Politicas Culturales para el Desarrollo (1998); Declaración Universal de la Diversidad Cultural (2001), International Network of Observatories in cultural policies (2004); : The art of living in Peace. Guide to education for a culture of peace (2004)

\section{Bibliografía}

APPADURAI, A. The Social Life of things. Cambridge. University Press. 1986. Del mismo autori: Disjunture and difference in the global cultural economy. Cambridge. 2000

CANCLINI, N. Hybrid Cultures: Strategies for Entering and Leaving Modernity. University of Minnesota Press. Minneapolis, 1995

CASTELLS, M. The power of Identity. Blackwell Publishers, Malden, Mass. 1997

GIDDENS, A. Modernidad e Identidad del yo. El yo y la sociedad en la época contemporánea. Ed. Península. Barcelona, 1997

MORENTE, M. El Patrimonio Cultural. Una propuesta alternativa al concepto actual de Patrimonio Histórico. Tesis Doctorales. Microfichas. Universidad de Málaga. 1996

OST, F. El Patrimonio y las generaciones futuras en BINDÉ, J. Claves para el siglo XXI. Ediciones UNESCO París. 2002. pág. 202- 208

REMOND-GOUILLOUD, M. La evolución de las ideas de Patrimonio en BINDÉ, J. Claves para el siglo XXI. Ediciones UNESCO París. 2002. pág. 200

REMOND-GOUILLOUD, M. Du Droit de tétruire. PUF. Paris 1997 